\title{
Trabalhadores, empresas e movimento sindical na ditadura militar brasileira (1964-1985): fontes e métodos
}

Trabalhadores, empresas e movimento sindical na ditadura militar brasileira (1964-1985): fontes e métodos

\author{
Heliene Nagasava \\ Escola de Ciências Sociais da Fundação Getúlio Vargas. Arquivo Nacional, Brasil \\ hnagasava@gmail.com
}

Larissa R. Corrêa

Pontifícia Universidade Católica do Rio de Janeiro, Brasil

larissa_correa@puc-rio.br

\section{Resumen:}

El propósito de este artículo es analizar un conjunto de fuentes disponibles para los estudios sobre el impacto de la dictadura militar brasileña en el movimiento sindical y los trabajadores. Además, también buscamos trazar un mapa de documentos que haga posible investigar el papel de las empresas como colaboradoras del régimen autoritario que estuvo vigente en Brasil entre los años de 1964 y 1985. A partir de la descripción de los archivos, sugerimos una reflexión metodológica sobre como comprender la historia de la dictadura militar desde la perspectiva de la historia social, es decir, "desde abajo". Por último, el artículo busca establecer un diálogo con el conjunto de las investigaciones realizadas sobre los trabajadores y el movimiento sindical en el ámbito de la Comisión Nacional de la Verdad (2011 a 2014), pensando en las posibilidades de ir más allá del trabajo ya realizado.

Palabras ClaVE: Movimiento sindical, Trabajadores, Empresas, Dictadura militar brasileña .

\section{ABstraCT:}

This article aims to analyze the impact of the Brazilian military dictatorship (1964-1985) on the labor movement. Besides, we also seek to map documents available to investigate the role of companies as collaborators of that authoritarian regime. From the description of the archives we suggest a methodological reflection on how to understand the history of military dictatorship from a social history perspective, that is, "from below". Lastly, this study seeks to establish a dialogue with the set of research conducted on workers and trade union movement by the Brazilian Truth Commission (2011 to 2014) thinking about the possibilities to deeper the analyses and the conclusions already done by this governmental Commission.

KEYWORDS: Trade unionism, Workers, Companies, Brazilian military dictatorship .

Como é possível acessar os registros da história dos trabalhadores e suas organizações produzidos durante o regime militar? De que forma os documentos remanescentes possibilitam analisar as ações dos trabalhadores e seus sindicatos? Como pesquisar a atuação da classe empresarial e sua colaboração com o regime? Ou ainda, é possível contar uma história da repressão aos trabalhadores vista "de baixo"? Essas questões foram exaustivamente discutidas no primeiro encontro da Red sobre Processos repressivos, empresas, trabajadores y sindicatos, realizado em março de 2018, em Buenos Aires, Argentina. O evento resultouuna criação da rede de pesquisadores interessados na investigação sobre o papel das empresas e empresários na repressão aos trabalhadores durante as ditaduras do Cone Sul. O grupo tem como propósito viabilizar a troca de experiências entre os estudiosos sobre os métodos de pesquisa, bem como o levantamento de fontes documentais que abordem aspectos da repressão aos trabalhadores e da colaboração entre regimes autoritários e grupos empresariais.

$\mathrm{Na}$ esteira dos debates travados no encontro de 2018, a proposta deste artigo é apresentar um mapeamento de fontes documentais referentes à história da atuação e repressão aos trabalhadores e ao movimento sindical, 
considerando ainda o papel dos grupos empresariais durante o regime ditatorial brasileiro. Para além da localização das fontes, nos interessa colaborar para o debate sobre as diferentes perspectivas metodológicas e suas implicações historiográficas no campo da história do trabalho. É fato que a historiografia da história do trabalho no Brasil observou nos últimos anos um aumento considerável da produção de estudos sobre o período da ditadura militar. Grande parte dessa produção mais recente surgiu impulsionada pelas pesquisas conduzidas para a composição do Relatório Final da Comissáo Nacional da Verdade (CNV). Para além da entrega do documento oficial que encerrou os trabalhos da Comissão- evento ocorrido em 2014 -, o próprio processo de produção das pesquisas, organizado por grupos temáticos, estimulou a continuidade e o aprofundamento dessas investigações.

Não se trata aqui de apresentar uma revisão historiográfica no campo da história do trabalho no período da ditadura militar brasileira, nem tampouco de apresentar um levantamento completo e exaustivo de conjuntos documentais. Nossa proposta de análise procura estabelecer um diálogo com o relatório temático produzido pelo Grupo de Trabalho da CNV intitulado "Ditadura e Repressão aos Trabalhadores e ao Movimento Sindical”, a fim de observar os conjuntos documentais utilizados para a investigação no âmbito da CNV, apontando também para outras fontes que podem ampliar o escopo da pesquisa sobre a política econômica e social voltada para os trabalhadores, e a repressão que incidiu sobre eles a partir de 1964.

Como resultado do relatório apresentado pelo GT, "Ditadura e Repressão aos Trabalhadores e ao Movimento Sindical", foram destacados nove pontos de análise que caracterizam a história dos trabalhadores e do movimento sindical na ditadura. Vale a pena reproduzi-los:

1. Os trabalhadores e seu movimento sindical constituíram o alvo primordial do golpe de Estado de 1964, das ações antecedentes dos golpistas e da ditadura a seguir imposta;

2. O golpe de 1964 e a ditadura subsequente decorreram de uma aliança civil-militar embasada em um projeto comum e numa ação articulada;

3. A ditadura de 1964 criou um novo regime fabril;

4. A articulação público-privada constituída no âmbito da ditadura de 1964 ampliou significativamente as formas de violência e repressão praticadas contra os trabalhadores;

5. Na ditadura de 1964 empresas estatais tornaram-se laboratórios de monitoramento e repressão;

6. Durante a ditadura de 1964 alterou-se a legislação econômica e trabalhista para viabilizar a superexploração dos trabalhadores e mais rápida aconcentração de capital;

7. $\mathrm{Na}$ esteira das violações de direitos mencionadas ocorreram as graves violações de direitos dos trabalhadores: prisões ilegais e arbitrárias, torturas, assassinatos, desaparecimentos forçados, ocultações de cadáveres;

8. A classe trabalhadora foi vítima de torturas que resultaram em sequelas físicas e psicológicas insuperáveis;

9. Tem-se notícia de muitas mortes e desaparecimentos forçados de trabalhadores, mas os números continuam inconclusivos ${ }^{1}$.

A partir dessas constatações é possível redimensionar diversos aspectos da repressão aos trabalhadores e suas ações de resistência. Nesse sentido, nossa proposta é traçar um levantamento de fontes documentais que permita o aprofundamento dessas análises. Longe de esgotar a pesquisa sobre a repressão aos trabalhadores e ao movimento sindical na ditadura, o relatório da CNV representa uma contribuição significativa para a compreensão do tema. Porém, entendemos que ele é um ponto de partida e ao mesmo tempoumareferência crucialpara o desdobramento e ampliação de um leque de questões ali apresentadas. Por exemplo, ainda sabemos pouco sobre as relações e práticas que configuraram a aliança entre empresários (empresas estatais e privadas) e o regime militar. No âmbito da repressão aos trabalhadores e ao movimento sindical encontramos dificuldades em denominar os limites da violência política perpetrada pelo Estado de Exceção e as formas de violência características dos regimes de trabalho impostos pelo sistema capitalista nos países em 
desenvolvimento. Quando nos voltamos para o tema das ações organizadas na luta contra o regime ditatorial, algumas questões já apontadas em artigo publicado por Larissa R. Corrêa e Paulo Fontes (2017) permanecem em aberto:

Como os militantes trabalhadores portadores de uma cultura própria do mundo operário e sindical lidavam com diferentes hábitos, vocabulários, leituras e modos de agir e pensar próprios dos militantes que vinham do movimento estudantil e das camadas médias? E ainda, quantos teriam participado de ações diretas contra o regime militar, sem, contudo, terem sido reconhecidos como militantes operários? Sua identidade específica como trabalhadores era diluída ao entrar para o movimento de guerrilhas? Por outro lado, seria importante compreender o que os trabalhadores pensavam sobre as ações da luta armada ${ }^{2}$.

As respostas para estas questões exigem o cruzamento de fontes e o emprego de diferentes metodologias, incluindo métodos quantitativos e qualitativos, bem como a chamada história a contrapelo, metodologia amplamente utilizada pela história social ${ }^{3}$. Visando o mapeamento de fontes sobre a história do trabalho e dos trabalhadores na ditadura militar, organizamos os acervos por conjuntos documentais produzidos no âmbito do Estado (arquivos e órgãos públicos), pela sociedade civil (centros de memória, coleções privadas e arquivos de sindicatos que conservam a memória das organizações do movimento sindical e dos trabalhadores), e documentos referentes aos grupos empresariais.

\section{ArQuivos E órgãos PÚBLICOS}

No contexto de redemocratização do país com o fim da ditadura, em 1985, e com a aprovação da nova Constituição, em 1988, os principais órgãos de repressão foram extintos e seus conjuntos documentais foram recolhidos para os arquivos públicos no final dos anos 1990. No nível estadual, as Delegacias de Ordem Política e Social - DOPS ou DEOPS - eram responsáveis pelo fichamento e controle da informação de pessoas, grupos ou entidades consideradas perigosas e que, portanto, deveriam ser monitorados pelo Estado. Os órgãos estavam vinculados às secretarias de Segurança dos Estados e tinham sido criados na década de 1940. Sua documentação perpassa grande parte do período democrático e ditatorial da história republicana do Brasil, e permite a compreensão dos principais objetos de perseguição pelo Estado. Com a sua extinção, no final dos anos 1990, os arquivos estaduais começaram a receber essa massa documental. Os três maiores conjuntos documentais produzidos por essas delegacias correspondem ao DEOPS/SP, ao DOPS/Guanabara e DOPS/Rio de Janeiro e o DOPS/PE. Todos esses conjuntos documentais possuem um fichário que remete a um conjunto de dossiês, replicando o método original de organização e recuperação da informação pelas polícias políticas. Atas de reuniões, cartazes e panfletos são alguns dos tipos documentais produzidos por sindicatos que foram apreendidos,salvaguardando indiretamentea história dessas entidades. Outros estados também possuem os acervos DOPS, porém muitos deles sofreram maior ou menor grau de destruição ${ }^{4}$.

Para que fosse evitada a perda de conjuntos documentais, uma série de políticas positivas para o recolhimento, tratamento técnico e abertura da documentação resultaram, em 2009, na criação do Centro de Referência das Lutas Políticas no Brasil (1964-1985) - Memórias Reveladas55. O Memórias Reveladas tem como objetivo reunir e divulgar informações sobre o período da ditadura, funcionando como articulador de uma rede de parcerias entre entidades públicas e privadas, com a coordenação do Arquivo Nacional. Uma das inúmeras iniciativas do Memórias Reveladas foi a criação de um banco de dados que pudesse reunir as informações dos acervos dos DOPS e de outros centros de memória sobre a repressão em um único local de busca. O Arquivo Nacional, tendo em vista a expertise no tratamento técnico de acervos, coordenou um grande projeto que auxiliou a descrição, digitalização e inserção das informações no banco de dados Memórias Reveladas ${ }^{6}$. É importante ressaltar que os acervos continuam sob guarda dos arquivos estaduais, tendo o Memórias Reveladas abrigado o sistema e espaço digital onde essas informações foram inseridas. Essa enorme iniciativa possibilitou que acervos dispersos pelo país pudessem ser acessados online por qualquer 
pessoa, permitindo uma grande ampliação nos escopos das pesquisas e a democratização da informação de perseguidos pela ditadura militar.

No nível federal, um ponto importante de mudança no recolhimento dos acervos do período da ditadura foi a transferência de três conjuntos documentais para o Arquivo Nacional, em 2005. Foram eles: o Conselho de Segurança Nacional - CSN, a Comissão Geral de Investigações - CGI e o Serviço Nacional de Informações - SNI.

O temido SNI, cabeça chave do SISNI -Sistema Nacional de Informações, foi um dos principais órgãos de monitoramento e repressão do período da ditadura. Em seus documentos estão registrados pedidos de busca e informação de militantes de organizações armadas e movimentos sociais, sindicalistas, funcionários públicos, políticos e até mesmo militares. Dossiês sobre entidades civis se misturam com relatórios de informantes sobre relações extraconjugais de perseguidos políticos, ilustrando a capilaridade e a profundidade do sistema de informações. Durante a ditadura militar brasileira, sindicalistas foram monitorados, presos e torturados, e sindicatos sofreram invasóes e tiveram seus documentos apreendidos. Muitos militantes destruíram os materiais produzidos pelas entidades na tentativa de evitar que eles fossem utilizados pelo Estado de exceção como provas. No entanto, com o recolhimento do acervo das polícias políticas, esses documentos puderam vir à tona e, em muitos casos, são a única cópia preservada da história do movimento trabalhista. Esse fundo documental recentemente foi migrado para o Sistema de Informação do Arquivo Nacional - SIAN e está disponível para pesquisa online ${ }^{7}$.

O SISNI também era composto pelas Assessorias de Segurança e Informação (ASI) e as Divisões de Segurança e Informação (DSI). Setores que monitoravam as ações dentro de órgãos e ministérios, respectivamente, da esfera administrativa federal. Um importante conjunto documental, ainda não recuperado, foi o produzido pela DSI do Ministério do Trabalho.

Apesar desse acervo não ter sido encontrado, uma conquista importante atribuída ao trabalho do GT "Ditadura e Repressão aos Trabalhadores" da CNV foi o resgate da documentação produzida pelo Ministério do Trabalho e Emprego (MTE) $)^{8}$, que se encontrava há décadas em estado de abandono pelo próprio órgão ministerial. Embora alguns historiadores tivessem conhecimento da existência de um arquivo de tamanho monumental e em condições precárias de conservação, foi com o apoio da $\mathrm{CNV}$ que os pesquisadores puderam visitar e pesquisar a documentação sob a guarda do MTE.

É necessária uma digressão sobre o conjunto documental produzido pelo Ministério do Trabalho. O órgão foi criado em 1930, vinculado com a Pasta da Indústria e Comércio;rapidamente,com o desenvolvimento da burocracia estatal,o órgão adquiriu capilaridade nacional, tendo presença em todos os estados do país. O volume documental produzido na sede da Pasta e em suas delegacias regionais se tornou colossal, e parte da documentação foi recolhida nos anos 1990 para o Arquivo Nacional. É sabido que duas das maiores delegacias regionais do Trabalho, São Paulo e Rio de Janeiro, enviaram parte dos seus documentos para a sede na capital federal, em Brasília, durante esse mesmo período.No entanto, eles não foram enviados para o Arquivo Nacional, sendo parte de uma segunda fase do projeto de identificação para recolhimento, que acabou não sendo executada. Foi essa massa documental que foi encontrada pela CNV. Pela primeira vez foram localizados processos completos sobre greves na ditadura, fichas de registro dos sindicatos do Rio de Janeiro e São Paulo, produzidas entre as décadas de 1940 e 1970. Por meio das fichas podemos recuperar alguns aspectos da história administrativa das entidades sindicais, bem como das lutas da categoria. Apesar dos esforços da CNV para que essa documentação fosse recolhida ao Arquivo Nacional ${ }^{9}$, o processo não pode ser concluído pela falta de identificação e pelo precárioestado de higienização. Atualmente, o acesso aos documentos é restrito e burocrático, pois o Ministério não conta com funcionários suficientes para salvaguardar os documentos ${ }^{10}$.

No entanto, a documentação recolhida para o Arquivo Nacional ${ }^{11}$ nos anos 1990 está completamente identificada e aberta à consulta pública. Através desses documentos é possível compreender o papel que o 
Ministério desempenhou durante a ditadura,tanto na área repressiva- como os processos de intervenção sindical -, como na de políticas públicas - como para previdência social e habitação.

Para além das intervenções sindicais e do controle das atividades do movimento sindical sistematicamente realizado pelo Ministério do Trabalho ao longo da ditadura militar brasileira é possível analisar os conflitos trabalhistas travados entre patróes, empregados e seus respectivos sindicatos, dirimidos pela Justiça do Trabalho. Criada em 1941, com o objetivo de harmonizar as relações entre capital e trabalho, a atuação dos tribunais trabalhistas representa um campo fértil para os pesquisadores das relações trabalhistas. Paralelamente ao aumento do número de pesquisas nesta área, ocorreu um movimento intenso de debates sobre a conservação e guarda dos processos trabalhistas produzidos pelos tribunais trabalhistas de todo o Brasil. Muitos tribunais regionais tornaram-se sensíveis a questão da urgência em estabelecer critérios arquivísticos que visassem a preservação e a viabilização do acesso desses documentos à pesquisa acadêmica. Dentre os tribunais regionais que estabeleceram uma política de preservação e acesso, destacamos o Tribunal Regional do Trabalho de São Paulo (TRT da $2^{\circ}$ região), o TRT de Campinas ( $15^{\circ}$ região), o TRT do Rio de Janeiro ( $1^{\circ}$ região), o TRT de Minas Gerais ( $3^{\circ}$ região), o TRT do Rio Grande do Sul ( $4^{\circ}$ região) e o TRT de Pernambuco ( $6^{\circ}$ região). Esses tribunais possuem conjuntos documentais, organização e políticas de acesso distintos. O TRT de São Paulo, por exemplo, graças ao convênio estabelecido entre esta corte trabalhista e a Universidade Estadual de Campinas, com recursos da Fapesp, microfilmou e digitalizou milhares de processos trabalhistas que haviam sido preservados pelo tribunal, referente ao período da década de 1940 e 1990. O resultado da parceria entre tribunal e universidade foi a construção de uma base de dados que conta com mais de 1.500 processos catalogados online, e que permite realizar pesquisas quantitativas e cruzamento de dados com outros tribunais ${ }^{12}$.

Conforme já consolidado em nossa historiografia do trabalho no Brasil, as fontes judiciais constituem registros importantes para o campo, permitindo o conhecimento das relações entre trabalhadores, Justiça do Trabalho e empregadores, representando uma fonte documental essencial para a compreensão de importantes processoshistóricos, políticos, econômicos e sociais do país. Mais particularmente sobre o papel da Justiça do Trabalho nos conflitos trabalhistas travados durante o período do regime militar, os processos de dissídios coletivos apresentam dados sobre as mudanças nas práticas de negociações coletivas após a instauração da política trabalhista lançada pelo governo do ditador Castello Branco (1964-1967), primeira gestão do regime militar. Os dissídios coletivos possibilitam averiguar as restrições impostas pelo Poder Executivo ao poder normativo dos juízes trabalhistas; permitem também analisar a retração do papel dos sindicatos na defesa dos direitos coletivos das categorias de trabalhadores, além da impossibilidade de negociar um aumento salarial que estivesse acima dos índices de aumento do custo de vida estabelecido pelo governo ditatorial ${ }^{13}$.

No âmbito dos dissídios individuais, a documentação produzida pela justiça trabalhista permite adentrar no âmbito dos conflitos individuais entre trabalhadores e empregadores dirimidos pela corte trabalhista. Por meio dos processos podemos acessar as demandas dos trabalhadores, a construção das narrativas do conflito e o modo como foram encaminhados pela Justiça e julgados por ela. É possível ainda conhecer as disputas travadas nos espaços fabris e aspectos das relações cotidianas de trabalho, seja no campo da produção fabril ou na prestação de serviços. A partir de 1964, sob o impacto da instauração do regime militar, a instituição trabalhista passou por uma fase de inflexão no modo de julgar os conflitos, considerando que as cortes trabalhistas também foram alvo de um movimento repressivo por parte do governo Castello Branco, que realizou expurgos e exonerações em diversos tribunais.

\section{Conjuntos documentais PRODUZidos PELA SOCIEDADE CIVIL}

Na década de 1970, em plena fase de recrudescimento da repressão do Estado aos grupos de oposição 
à ditadura militar, as universidades públicas federais e estaduais criaram espaços para a guarda e preservação de documentos referentes às histórias das organizações da esquerda, dos movimentos sindicais, e de militantes de diversas correntes políticas e ideológicas. Temendo a destruição destes conjuntos documentais pelo aparato repressivo da ditadura militar, a Universidade Estadual de Campinas (Unicamp), em parceria com a Fundação de Amparo à Pesquisa do Estado de São Paulo (Fapesp), criou o Arquivo Edgard Leuenroth (AEL) no ano de $1974^{14}$. Primeiramente recebeu a coleção de impressos do próprio militante anarquista Edgard Leuenroth, e, pouco a pouco, o centro de memória foi se constituindo num dos centros de pesquisa mais importantes para a história das esquerdas e dos movimentos sociais na América Latina. Durante o período de redemocratização ocorrido entre o final da década de 1970 e os anos 1980, o AEL abrigou documentos produzidos pelos chamados novos movimentos sociais, oriundos dos grupos feministas, LGBT e estudantil. No campo dos estudos da história social do trabalho na ditadura militar, o AEL preserva documentação sobre fábricas, sindicatos e documentos do Departamento Intersindical de Estatística e Estudos Socioeconômicos (DIEESE). Recentemente, a instituição recebeu a coleção privada de documentos do líder sindical José Ibrahim, militante exilado no período da ditadura e um dos presos políticos trocados pelo embaixador norte-americano Charles Elbrick. Ibrahim foi um dos líderes da greve de Osasco de 1968, uma das principais greves ocorridas na ditadura ${ }^{15}$.

Criado em 1987, em meio ao processo de redemocratização no Brasil e num período em que a sociedade civil receava transferir a documentação dos movimentos sociais para os arquivos públicos, o Centro de Documentação e Memória da Universidade Estadual Paulista (CEDEM/ UNESP) surgiu como iniciativa de um grupo de professores da área das Ciências Humanas e representa um dos principais centros de memória sobre memória social e memórias dos movimentos político-sociais brasileiros contemporâneos. Um acervo que reúne documentação preciosa sobre os movimentos estudantiles, da luta pela anistia e redemocratização, das organizações clandestinas de oposição à ditadura militar, e sobre o movimento sindical; muitos documentos produzidos pelas próprias organizações clandestinas que resistiram às perseguições do aparato repressivo. Essas coleções permitem, inclusive, analisar como esses movimentos se constituíam em diálogo um com os outros, sendo os jornais produzidos pelo movimento estudantil, por exemplo, uma fonte importante para conhecer a situação dos trabalhadores e dos sindicatos durante o período autoritário ${ }^{16}$.

No Rio de Janeiro, também no ano de 1987, foi fundado o Arquivo de Memória Operária do Rio de Janeiro (AMORJ), um núcleo de pesquisa e documentação administrado pela Universidade Federal do Rio de Janeiro (UFRJ). Inicialmente o AMORJ guardava a documentação reunida de pesquisas realizadas pelo corpo docente do Departamento de Ciências Sociais do Instituto de Filosofia e Ciências Sociais da UFRJ. Pouco a pouco foi sendo incorporada a documentação referente às trajetórias de intelectuais e militantes de esquerda, lideranças sindicais e políticas. Sobre a repressão da ditadura militar aos trabalhadores, destacamse os fundos sobre os "bancários perseguidos pela ditadura e a luta pela anistia"; o Movimento e Organização dos Trabalhadores Rurais no Brasil; o Coletivo Gregório Bezerra; a Pastoral do Trabalhador, entre outros.

O Centro de Documentação e Memória Sindical da Central Única dos Trabalhadores (CEDOC/ CUT) representa também um importante núcleo de pesquisa para a história do trabalho e dos trabalhadores no Brasil durante o regime militar e o período democrático após a Constituição de 1988. Criado em 1999, o CEDOC abriga a história da CUT e do movimento sindical em geral. Dentre os documentos mais pesquisados, destacam-se os periódicos, impressos, cartazes do movimento sindical (campas e eventos) e as resoluções dos congressos e plenárias. A documentação do centro também permite analisar aspectos das relações internacionais sindicais travadas a partir da década de 1980.

Outras duas ações relevantes na área de pesquisa e preservação da história do movimento dos trabalhadores e seus sindicatosforama criação da entidade Intercâmbio, Informações, Estudos e Pesquisas (IIEP) e do Centro da Pastoral Vergueiro (CPV), ambas localizadas na cidade de São Paulo. O IIEP surgiu nos anos 2000 para abrigar a documentação da Oposição Sindical dos Metalúrgicos de São Paulo (OSMSP). Além da documentação, a entidade atua como centro de pesquisa, reunindo sindicalistas, acadêmicos e educadores. O IIEP colaborou diretamente com a produção do relatório do GT Trabalhadores e Movimento sindical 
e desenvolveu projetos de pesquisa que são referências para a história e memória dos trabalhadores durante a ditadura, como o Investigação Operária, realizado em parceria com a Comissão de Anistia, e o projeto Memória da OSM-SP ${ }^{17}$.

O Centro da Pastoral Vergueiro (CPV) reúne documentação produzida pelos movimentos sociais nas décadas de 1970 e 1980 e atuação das organizações católicas. Fundado em 1973, como uma iniciativa dos frades dominicanos e a participação de estudantes e militantes da esquerda, por décadas o CPV resistiu às condições de precariedade e descaso público para com a história dos trabalhadores e dos movimentos sociais, organizando, catalogando e dando acesso à documentação com recursos e esforços da própria militância. O seu acervo extenso abriga milhares de documentos textuais, iconográficos, sonoros, com destaque para a coleção de 77 mil periódicos e livros que tratam da história dos movimentos sociais, de intelectuais, artistas, militantes, organizações partidárias, grupos de Igreja, com destaque para os registros das atividades das oposições sindicais no período ditatorial ${ }^{18}$. Atualmente, o CPV encontra-se alocado no AEL/ Unicamp, para tratamento da documentação.

Acervos localizados em outros países também são de extrema importância para compreender os mecanismos adotados pela ditadura e a força de seus agentes em contrapor-se à pressão internacional. $\mathrm{O}$ fundo Brasil Nunca Mais é um exemplo da luta coletiva para a salvaguarda da documentação pública, na busca da comprovação de violações de direitos humanos. Em 1979, advogados dos presos políticos com membros do Conselho Mundial de Igrejas copiaram secretamente 710 processos judiciais do Superior Tribunal Militar que relatavam as torturas ${ }^{19}$. Por motivos de segurança, a documentação foi microfilmada e enviada para os Estados Unidos, e, posteriormente, uma cópia foi guardada no acervo da Universidade de Campinas (Unicamp). Um grande projeto coletivo recente, com o apoio da CNV, permitiu que essa documentação fosse integralmente digitalizada e indexada em uma plataforma acessível online ${ }^{20}$. Por meio do banco de dados do fundo Brasil Nunca Mais é possível traçar o perfil e as origens dos militantes processados e trabalhar com dados quantitativos e cruzar informações, observando, por exemplo, quantas mulheres, operários, trabalhadores rurais e estudantes foram envolvidos nas investigações conduzidas pelo aparato repressivo do regime militar.

Nos Estados Unidos, outro importante projeto com documentos sobre a ditadura brasileira é desenvolvido, o OpeningtheArchives ${ }^{21}$. Com o objetivo de digitalizar e indexar documentos do governo estadunidense sobre o Brasil durante as décadas de 1960 a 1980, a Brown University passou a abrigar um banco de dados cujos registros aprimoram o conhecimento sobre a relação entre os dois países, permitindo a compreensão da visão americana sobre a violação de direitos humanos, o desenvolvimento econômico, a resistência armada, a repressão política, dentre outros temas relativos ao Brasil. Os documentos governamentais também possuem o mérito de apontar os responsáveis pelas políticas de repressão e o papel que eles desempenharam em uma gama de assuntos, seja nas práticas de tortura, seja no modelo sindical a ser implantado, como apontou a CNV.

\section{DOCUMENTAÇÃO SOBRE GRUPOS EMPRESARIAIS}

O Arquivo Nacional também abriga coleções produzidas por entidades privadas que tiveram papel determinante no golpe de 1964, com o Instituto de Pesquisas e Estudos Sociais - IPES. Fundado em 1962, no Rio de Janeiro, tinha como objetivo congregar um grupo de empresários em uma campanha contra o governo do presidente João Goulart, deposto pelo golpe. O IPES utilizou dos meios de comunicação para propagar campanhas contra o comunismo e a favor da livre iniciativa, além de financiar outras entidades como a Campanha da Mulher pela Democracia (CAMDE). O acervo encontra-se completamente digitalizado e acessível online, via SIAN. O Centro de Pesquisa e Documentação (CPDOC) da Fundação Getúlio Vargas, no Rio de Janeiro, abriga o arquivo privado de um dos membros do IPES, o empresário da indústria química 
e farmacêutica Paulo Ayres Filho, contendo atas, relatórios, estatutos e correspondências que envolvemas atividades do empresário na entidade anticomunista ${ }^{22}$.

Outro conjunto documental que foi possível ser consultado após a pressão da Comissão Nacional da Verdade e da Comissão da Verdade de Volta Redonda foi o acervo da Companhia Siderúrgica Nacional CSN. A empresa, privatizada nos anos 1990, guardou em seus depósitos toda a documentação do período em que foi pública, desde a sua criação em 1941, como parte do modelo desenvolvimentista que estava sendo aplicado no Brasil. Em seus registros está a história de milhares de trabalhadores que se mudaram para a cidade de Volta Redonda (conhecida como a Cidade do Aço) e de suas lutas.

A documentação de empresas tem sido particularmente útil para a recuperação e reparação de uma parte da história nacional, em que observamos a colaboração e pactuação entre setores das elites civis e as Forças Armadas em relação às políticas econômicas e repressivas da ditadura militar. A investigação das violações de direitos humanos no caso da montadora Volkswagen é parte essencial da contribuição do Relatório Final da Comissão Nacional da Verdade. A empresa não apenas se beneficiou das políticas trabalhistas que efetuaram a perda de direitos dos metalúrgicos, mas também foi responsável pela repressão e tortura dentro de suas portas. Porém, o acesso aos documentos produzidos pelas próprias empresas ainda é muito limitado. Muitos pesquisadores têm enfrentado os obstáculos criados pelas corporações para barrar a investigação histórica. Nesses casos, muitos estudiosos têm recorrido aos documentos da polícia política e outros documentos públicos, como os arquivos diplomáticos, como estratégia para analisar a atuação dos grupos empresariais.

Apesar de não ter sido utilizado pela CNV, o acervo da Organização Internacional do Trabalho ${ }^{23}$ (OIT)contém registros das denúncias contra o governo brasileiro no que diz respeito à prisão e tortura de sindicalistas e intervenção em sindicatos. Sendo signatária de convenções que asseguram a liberdade de associação, a ditadura brasileira passou a violar um conjunto de normas trabalhistas internacionais e foi denunciada na OIT. Esses processos refletem a opinião das federações sindicais internacionais sobre a situação política no país, e como a OIT pressionou o governo brasileiro a prestar esclarecimentos públicos sobre as suas ações. Esses documentos ainda foram pouco estudados por dois motivos: os processos sobre esse tema não estão plenamente abertos (grau de sigilo de 50 anos), e somente parte das informações podem ser consultadas online. No entanto, as informações contidas nesses documentos possuem um enorme potencial para pesquisas futuras.

\section{CONSIDERAÇÕES FINAIS}

A Comissão Nacional da Verdade permitiu que o período da ditadura militar no Brasil se tornasse tema do debate público e que os excessos e as violações cometidas pelo Estado fossem expostos. A cerimônia de instalação dos trabalhos da CNV realizada na sede do governo federal, o Palácio do Planalto- no dia 16 de maio de 2012 pela presidenta Dilma Rousseff - foi um marco nacional do processo de justiça de transição. Rousseff, ex-militante da luta armada, presa e torturada durante a ditadura brasileira, em seu discurso afirmou:

A ignorância sobre a história não pacifica, pelo contrário, mantêm latentes mágoas e rancores. A desinformação não ajuda apaziguar, apenas facilita o trânsito da intolerância. A sombra e a mentira não são capazes de promover a concórdia. O Brasil merece a verdade. As novas geraçóes merecem a verdade, e, sobretudo, merecem a verdade factual aqueles que perderam amigos e parentes e que continuam sofrendo como se eles morressem de novo e sempre a cada dia ${ }^{24}$.

Não coincidentemente, nessa ocasião, passou a vigorar a Lei de Acesso à Informação (LAI ${ }^{25}$, que permitiu que acervos públicos produzidos no período da ditadura fossem acessados de forma irrestrita, pois ali estavam registradas as provas do abuso estatal, e que, portanto, não poderiam ter nenhum grau de sigilo. Grande parte dos acervos públicos citados nesse artigo passou a ser disponibilizada online a partir desse marco jurídico. 
O próprio acervo da CNV se encontra aberto e disponível online ${ }^{26}$. Nesse conjunto documental é possível ter acesso aos arquivos pesquisados que geraram o Relatório Final, aumentando sobremaneira as fontes para pesquisa nesse período. Apesar das contribuições dos trabalhos realizados pela $\mathrm{CNV}$, ainda é necessário avançar em diversas áreas da justiça de transição. É fato que o golpe de 2016, que levou ao afastamento da presidenta Dilma Rousseff e a subsequente eleição de um presidente representante da ideologia da extremadireita no Brasil,representouum retrocesso, talvez incontornável, no processo de desenvolvimento das medidas políticas e jurídicas voltadas para a reparação das violações aos direitos humanos cometidas durante a ditadura militar. De toda forma, é dever da sociedade civil comprometida com os valores democráticos e com o Estado de direito não deixar que os avanços e conquistas obtidas pela CNV sejam ocultados por um projeto político de cunho antidemocrático, que busca estabelecer o revisionismo do período autoritário e até mesmo a exaltação de torturadores e do regime militar. Nesse sentido, os acervos apontados nesse artigo visam contribuir para que novas pesquisas possam ser desenvolvidas, e para que o lugar da luta dos trabalhadores e de suas entidades sindicais seja reconhecido.

\section{Notas}

1 Texto acessível em: https://trabalhadoresgtcnv.wordpress.com/, acessado em 14 de maio de 2019.

2 Correa, Larissa R. \& Fontes, Paulo. As falas de Jerônimo: Trabalhadores, sindicatos e a historiografia da ditadura militar brasileira. Anos 90, Porto Alegre, v. 23, n. 43, p. 129-151, jul. 2016.

3 Marilena de Souza Chauí, em seu prefácio "Historia a contrapelo" escrito para o livro de Edgar De Decca, O silêncio dos vencidos, inspirada em Walter Benjamin, apresenta uma reflexão sobre a necessidade de escovar a história a contrapelo, de forma a revelar como a história oficial oculta a história dos vencidos e forja uma narrativa histórica construída pelos vencedores. De Decca, Edgar Salvadori. 1930 - o silêncio dos vencidos. São Paulo: Brasiliense, 1986.

4 Sobre a organização do arquivo do Deops de São Paulo, ver: Aquino, Maria Aparecida de et.al. Dossiês DEOPS/ SP: radiografias do autoritarismo republicano brasileiro, vol. 1 a vol. 5. São Paulo: Arquivo do Estado/Imprensa Oficial do Estado de São Paulo, 2002; Duarte, Leila Menezes \& Araújo, Paulo Roberto Pinto de. A contradita - polícia política e comunismo no Brasil, 1945-1964. Rio de Janeiro: Arquivo Público Estado do Rio de Janeiro, 2013.

5 Ver: http://memoriasreveladas.gov.br/index.php/historico, acessado em 28 de maio de 2019.

6 Devido à migração de sistemas, o Banco de Dados Memórias Reveladas pode ser acessado em dois sistemas diferentes, o primeiro via http://base.memoriasreveladas.gov.br/mr/seguranca/Principal.asp e o segundo, que se tornará permanente, após a migração, o http://pesquisa.memoriasreveladas.gov.br/mrex/consulta/login.asp, acessados em 28 de maio de 2019.

7 Ver: http://arquivonacional.gov.br/br/?option=com_content\&view=article\&id=161, acessado em 24 de maio de 2019.

8 Última denominação do órgão

9 Ver: https://anpuh.org.br/index.php/2015-01-20-00-01-55/noticias2/diversas/item/1372-comissao-da-verdade-tem -acesso-a-dados-do-min-do-trabalho-sobre-perseguicoes, acessado em 14 de maio de 2019.

10 Sobre a extinção do Ministério do Trabalho, ver: http://www.dmtemdebate.com.br/o-ataque-ao-ministerio-do-trabal ho/ e https://www.cafehistoria.com.br/por-que-ministerio-do-trabalho-foi-criado/. Acessados em 28 de maio de 2019.

11 O acervo físico se encontra no Arquivo Nacional, Coordenação Regional (COREG), em Brasília. http://www.arquivo nacional.gov.br/br/?option=com_content\&view=article\&id=593. Acessado em 28 de maio de 2019.

12 Ver: https://www.ifch.unicamp.br/cecult/dissidios/busca, acessado em 17 de maio de 2019.

13 Ver: Corrêa, Larissa Rosa. "A rebelião dos índices: política salarial e Justiça do Trabalho na Ditadura Civil-Militar (1964-1968)”. EmÂ.de Castro Gomes, \&F. Teixeira da Silva,A Justiça do Trabalho e sua história. Campinas: editora da Unicamp, 2013.

14 Ver: https://www.ael.ifch.unicamp.br/acervo.

15 Sobre a trajetória militante do sindicalista José Ibrahim, ver: Chotil, Mazé Torquato. José Ibrahim: o líder da primeira grande greve que afrontou a ditadura. São Paulo: Alameda Editorial, 2018.

16 Ver, por exemplo, fundo Roberto Morena (1915 - 1978); Instituto Roberto Morena (1928 - 1995); Coleção do ASMOB - Clandestinidade, Exílio e Resistência (1964 - 2010); Fundo Oboré Editorial (1970 a 2000). https://www.cedem.une sp.br/\#!/guia-do-acervo/, acessado em 17 de maio de 2019. 
17 Ver: IIEP. Memórias resistentes, memórias residentes. Lugares de memória da Ditadura Civil-Militar no município de São Paulo. São Paulo: Secretaria Municipal de Direitos Humanos e Cidadania/ Coordenação de Direito à Memória e à Verdade, 2017.

18 Marco Aurélio Santana conceitua as oposições sindicais como um "agrupando militantes egressos ou não da experiência da luta armada e/ou militantes ligados à Igreja progressista, este setor apresentava uma plataforma que tinha como centro o combate à estrutura sindical corporativa a partir de um intenso trabalho de base via comissóes de fábrica. Sua maior expressão estava na Oposição Sindical Metalúrgica de São Paulo (OSM/SP) e podia apresentar posição que ia desde a aceitação do trabalho conjunto com o sindicato oficial até setores contrários a este tipo de articulação". Santana, Marco Aurélio. O “novo" e o "velho" sindicalismo: análise de um debate. Revista de Sociologia e Política, Curitiba, 10/11, 1998, pp. 19-35.

19 Arns, Dom Paulo Evaristo. (coord.) Brasil: Nunca Mais. Editora Vozes, 33a Edição, Petrópolis, 2003.

20 Ver: http://bnmdigital.mpf.mp.br/pt-br/, acessado em 28 de maio de 2019.

21 Ver: https://library.brown.edu/create/openingthearchives/en/, acessado em 28 de maio de 2019.

22 Ver: http://www.fgv.br/cpdoc/guia/detalhesfundo.aspx?sigla=PAF, acessado em 05 de junho de 2019.

23 Ver: https://www.ilo.org/global/lang--es/index.htm, acessado em 28 de maio de 2019.

24 Ver: http://www.biblioteca.presidencia.gov.br/presidencia/ex-presidentes/dilma-rousseff/discursos/discursos-da-pres identa/discurso-da-presidenta-da-republica-dilma-rousseff-na-cerimonia-de-instalacao-da-comissao-da-verdade-brasili a-df, acessado em 04 de junho de 2019.

25 Ver: http://www.planalto.gov.br/ccivil_03/_ato2011-2014/2011/lei/112527.htm, acessado em 04 de junho de 2019.

26 Ver: http://www.arquivonacional.gov.br/br/ ?option=com_content\&view=article\&id=161, acessado em 04 de junho de 2019. 